\title{
THE EFFECT OF OBSTRUCTION ON PRESSURE DISTRIBUTION
}

\section{IN THE DIVERGENCE RIBS DUCT AN EXPERIMENTAL STUDY}

\author{
ABBAS SAHI ${ }^{1} \&$ RIYADH S. AL-TURAIHI ${ }^{2}$ \\ ${ }^{1}$ Department of Mechanical Engineering, University of Kerbala, Kerbala, Iraq \\ ${ }^{2}$ Department of Mechanical Engineering, University of Babylon, Hilla, Iraq
}

\begin{abstract}
An experimental study is carried out of two-phase flow phenomena around obstruction in a divergence rib rectangular duct for two opening divergence angles. The experiments are performed in the duct with the water - air flow with various water and air discharges. The purpose of these experiments to visualize the two phase flow phenomena in addition to studying the effect of the pressure difference through the divergence with the presence of the obstruction. All the experimental data in this study are obtained by utilizing a pressure sensor and visualized by a video camera for different water discharges $(5,10,15 \mathrm{l} / \mathrm{min})$, different air discharges $(8.33,10.83,13.33 \mathrm{l} / \mathrm{min})$ and the opening angles are 10 and 15 degree. The results show that when the opening divergence angle increases from(10 to 15$)$ at constant air and water discharge, the pressure difference through the inlet and the outlet of the divergence ribs rectangular duct section decreases by $11 \%$.
\end{abstract}

KEYWORDS: Two-Phase Flow, Obstruction \& Divergence Ribs Rectangular Duct

Received: Jul 21, 2018; Accepted: Aug 11, 2018; Published: Sep 03, 2018; Paper Id.: IJMPERDOCT201828

\section{INTRODUCTION}

Two-phase flow is defined as two-phase flow simultaneously in the same pipe, like gas and liquid, gas and solid, two dissimilar liquids or liquid and solid. The most complex of these types are the flow of gas liquids due to the compressibility and deformation of both phases. Two-phase flow can be often met in chemical or mechanical engineering applications, oil wells, power generation, reactors, boilers, condensers, evaporators and combustion systems. Usually valves exist in transporter pipes for vapor and water in a steam turbine or boiler. These valves are geometrical singularities, as divergence or convergence, which may greatly affect the behavior of two-phase flow, including pressure change, void fraction distribution and flow pattern. Therefore, specific study is a significant issue when the application concerns industrial safety valves. There are numerous studies of two-phase flow in straight channels; however, in contrast to the studies of two-phase flow in divergence, there are somewhat fewer studies of convergence, bends and other types of singularities. The purpose of studying these geometries is to find how these geometrical accidents affect the two-phase flow regimes and pressure distribution; especially, the understanding of the flow in such basic geometries can lead to an improved design of safety systems. Zhu et al. (2009) conducted a numerical study of the effect of a hydrofoil on the distribution of bubbles for the bubble flow of different ranges of attack angles and Reynolds number. It was observed that the effect of the attack angle was small at a low Reynolds number, but the effect increased with the increase in Reynolds number. It was also observed that the angle of attack on the distribution of the bubble was clearer at the angle of 20 instead of 10 degrees. Edurne (2009) performed an experimental investigation of the development of intermittent flows in 
horizontal tubes in order to attain a thorough physical understanding of the internal configuration of two-phase flow regimes. The differences between the slug and the plug flow were explained and the effect of slug void fraction on the flow characteristics and the behavior of the dispersed bubbles in the slug body were examined. Kourakos et al. (2009) investigated horizontal two-phase flow (air-water) in progressive and sudden enlargement. The static pressure development was measured and flow regimes visualization was carried out. Compared to previous surveys, a deviation with Chisholm's model and with Jannsen's model was 10\% and 5\% for axisymmetric sudden enlargement. For progressive enlargement, the greatest pressure recovery was in the case of the smallest opening angle (at the same surface area ratio). The lowest pressure recovery happened for a sudden enlargement geometry with the same flow conditions. The static pressure recovery along the pipe was compared with $C F D$ simulations and literature surveys; satisfactory acceptability was observed. Finally, flow visualization showed that bubbly flow may depart to plug, or annular in the downstream of the divergent section. Deniz (2012) experimentally investigated the Pressure drop of two-phase flow (water-air) through an adiabatic horizontal channel with Smooth expansion. Measurements of the pressure were carried out at four regions: injector, upstream, expansion section, and downstream pipes. Two injectors with different distribution holes were used: inline injector and circular injector. This study showed that the influence of volumetric void fraction on pressure drop at the injector was more than the other regions due to the jet effect of the air injected into the water. It also showed that when the in-line injector was used, the pressure recovery caused by expansion was higher. Ansari et al. (2012) experimentally studied the two-phase flow (air-water) using ribbed and smooth horizontal rectangular channels to illustrate the influence of rib height on the regime boundaries, as the flow map was studied. Three ribs with heights of 1,2, and $4 \mathrm{~mm}$ were used; the rib pitch and width were $50 \mathrm{~mm}$ and pitch $10 \mathrm{~mm}$, respectively. The ribs were located in the channel at three different locations: the bottom wall, the top wall, and both the bottom and top wall. It was concluded that the effect of the ribs when located on both the bottom and top wall was clearer than in other cases. It was found that increasing of the rib height initiated hydro-dynamical instability at lower fluid velocities. Abadie et al.'s (2012) results showed that when the flow rate ratio of liquid and gas increases, the length of the slug and bubble increases. A numerical study of the hydrodynamic properties of the two-phase flow in the channel and small tubes was also carried out. Al-Turaihi (2013) undertook an experimental study of a two-phase flow (air-water) around a straight hydrofoil in a rectangular channel with different angles of attack and different water and air discharges. The results of this work demonstrated that the pressure difference increased through the channels when the angle of attack straight hydrofoil increased with both water and air flow rates being constant or when both water and air flow rates increased with the angle of attack being constant. Al-Turaihi (2013) undertook experimental and numerical studies of the two-phase flow around multi-shape obstacles (circular cylinder, square cylinder, and triangular cylinder) through a rectangular channel with $10 \times 3 \times 70 \mathrm{~cm}$. Experiments were conducted in the duct with air-water flow with various air and water flow rates. The results showed that when discharge of air or water increases, great turbulence appears, which generates more bubbles and waves and the mean pressure difference increases. In addition, in a water slug, the velocity of bubbles was slower than the water. Ahmadpour et al. (2016) conducted a numerical simulation of the two-phase flow (water-air) through divergence / convergence of constant opening

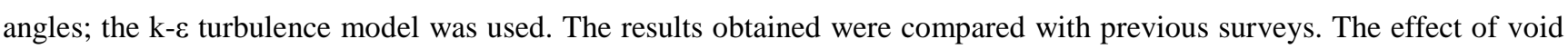
fraction, opening angle and Reynolds number was studied on pressure distribution inside a test channel. 


\section{EXPERIMENTAL SETUP}

An experimental rig was constructed to study the two-phase flow phenomena around the obstruction inside a divergence ribs rectangular duct. The equipment used for the experimental test and the measuring system is illustrated in Figures $1 \mathrm{a}$ and $1 \mathrm{~b}$. Two test sections were used with opening angle of 10 and 15 degrees, as illustrated in Figure 2 . The cross sectional area of these test sections was $2 * 6 \mathrm{~cm}$ before the divergence section, the length was $0.5 \mathrm{~m}$ long, while the section area was $2 * 8 \mathrm{~cm}$ after the d section with a length of $0.5 \mathrm{~m}$. The test section was manufactured from a Perspex sheet with a thickness of $1 \mathrm{~cm}$. The divergence section has four ribs, two ribs on each side with dimensions $0.5 * 0.5 * 2 \mathrm{~cm}$. The purpose of these ribs is to create strong turbulence intensity inside the diverging section by breaking the laminar-sub layer leading to rapid mixing between the phases. The abstraction used to be made from a Perspex sheet (1 cm thickness) with dimensions as shown in Figure 3. The experimental rig equipment consists of the following:

- $\quad$ Main water tank of capacity 500 litters.

- Water pumps with quantities (5-480) L/min, head (5-20) m, Power (1.5 KW) and $1410 \mathrm{RPM}$.

- Valves and tubing system for water (1.25) in.

- A flow meter (float type) was utilized to measure the discharge of water entered in the test section, with range 535 .

- Air compressor was utilized for air processing with a specification of a capacity (0.5 m3) and a maximum pressure of (16 bar).

- $\quad$ Air flow meter was used to measure the discharge of air that enters the duct with a range of (5.833-58.33 1/min).

- Valves and piping system for air $(0.5)$ in.

- Pressure sensors which were utilized to measure the pressure field with a range of (0-1 bar) and these pressure sensors were distributed along the test channel with an accuracy of $(0.1 \%)$.

- An interface was utilized to connect the pressure sensor to personal computers. The interface converts the voltage (analog) signal from the pressure sensors into a digital signal that can be read through a software program (DaLi08) run on the personal computer. A universal data logger (UDL100) was used. It had high accuracy and resolution, sampling period of (750 ms), and channel isolation voltage of (400 volts).

- A Sony digital camera of DSC-W220 model used to show the behavior of the two phase flow through a channel.

\section{EXPERIMENTAL PROCEDURE}

After building the system and installing all the measuring devices, the system was operated several times to confirm that there was no leak or any operating mistakes. During this work, eighteen experiments were performed. All the tests were achieved by taking different values of water discharges and different values of air discharges, as shown in Table 1 .

- Turn on the water centrifugal pump to pump the water from the water tank.

- The water valve was opened until the discharge in the flow meter reached the first value of the water discharge. 
- $\quad$ Turn on the air compressor.

- The air valve was opened until the volume rate in the flow meter reached the first value.

- The pressure begging measured by the sensors located at four points along the test channel where it can be read through computer software. And the image of the motion of two phase flow was taken by Sony digital camera..

- The water discharge was fixed at the first value and the air discharge was increased, until finish all the air discharges values.

- Repeat all above steps with a new water discharge value, until finish all the water volume flow rate.

Table 1: Values of Work Conditions used in Experiments

\begin{tabular}{|c|c|}
\hline $\begin{array}{c}\text { Water Discharge } \\
\text { Llmin }\end{array}$ & $\begin{array}{c}\text { Air Discharge } \\
\text { Llmin }\end{array}$ \\
\hline 5 & 8.33 \\
\hline 10 & 10.83 \\
\hline 15 & 13.33 \\
\hline
\end{tabular}

\section{RESULTS AND DISCUSSIONS}

\subsection{Effect of Pressure Difference}

Figures $4 \mathrm{a}$ and $4 \mathrm{~b}$ represent the mean pressure difference with air discharge for different values of water discharge for opening angles at 10 and 15 degrees. Mean while, Figures 5a and 5b represent the mean pressure with water discharge for different values of air discharge at the same opening angles. It can be seen from these figures that the pressure difference increases with increasing discharge of air or water for both the 10 and 15 opening angles. It was observed, too, that the difference in pressure for the opening angle 15 is less than the difference in pressure at the opening angle 10 at the same air and water discharge because the eddies are more in the case of angle 15 because of the presence of the additional flow area, leading to make the difference in pressure less than the case of opening angle of 10 degrees.

\subsection{Effect of Water Discharge on Pressure Profile}

Figures $6 a, 6 b$ and $6 c$ and Figures $7 a, 7 b$ and $7 c$ show the effect of increasing water discharge on pressure profiles at four points along the test channel for both angles, 10 and 15 degrees respectively, with different values of air discharge. It was observed that the pressure increases with increasing discharge of water. It was also observed that the values of pressure for the test section with an opening angle of 15 were higher than the values of pressure for the test section with an opening angle of 10 .

\subsection{Effect of Air and Water Discharge}

Figures $8 \mathrm{a}, 8 \mathrm{~b}$ and $8 \mathrm{c}$ represent images for the two-phase flow behavior around an obstruction in the divergence ribs rectangular duct for water discharge $(Q w=51 / \mathrm{min})$ and air discharges $(Q a=8.33,10.833$ and $13.3331 / \mathrm{min})$, respectively, for the opening angle of expansion of 10 degrees. Figure 8a shows that the number of bubbles is less and the volume of the bubble is small due to the air and water discharges being low. Also, with the increase in air discharge, the volume and number of bubbles increases, as in Figure $8 \mathrm{~b}$. With the continuing increase of air discharge, the turbulence in flow and velocity of eddies around the obstruction is higher compared with low air discharge cases, as shown in Figure 8c. Figures $9 \mathrm{a}, 9 \mathrm{~b}$ and $9 \mathrm{c}$ represent images of water discharge $(Q w=10 \mathrm{l} / \mathrm{min})$ and air discharges $(Q a=8.33,10.833$ and 13.333 
1/min), respectively, for the opening angle of expansion of 10 degrees. These figures explain that the volume of the bubbles is smaller compared to the case of $Q w=5 \mathrm{l} / \mathrm{min}$ at the same discharge of the air with an increase in the velocity of bubbles. Figures 10a, 10b and 10c show images for the two-phase flow at $Q w=15 \mathrm{l} / \mathrm{min}$. These figures show that the increase in discharge of the water makes the flow, unstable and increases in disturbance; as also observed, eddies around the obstruction are stronger. Generally, increased discharge of air or water leads to increased velocity of the bubbles and causes more turbulence of the flow and, thus, leads to configuration of more of the bubbles around the obstruction. It was also observed that the increased water discharge has a greater effect on the turbulence of flow than the increased discharge of air; as the obstruction has a clearer effect for generating eddies when the volume of the bubbles is bigger.

\subsection{Effect of Time Evolution of Pressure}

Figure 11 represents the effect of time evolution of pressure obtained by experiments for water discharge Qw=5 1/min and air discharge $\mathrm{Qa}=8.333$ 1/min through the test section with an opening angle of 15 degrees. It has been shown that pressure sensor readings fluctuated with time because of the two-phase flow (air-water). This fluctuation increases with increased air or water discharge because of the high inertia force in the two-phase flow. Therefore, the pressure reading is calculated by taking the mean value of the pressure sensor reading during 3 min values of pressure for the test section with the opening angle.

\subsection{Visualization and Flow Pattern Maps}

By observing the flow during the test section, we observe that the current flow pattern at the downstream is the churn flow, while after the divergence section and due to the presence of the obstruction and ribs, this lead to the reduction of the velocity of the mixture, which leads to the appearance of the slug flow, as shown in Figure 12. Figure 13 shows the flow pattern map at the downstream. A common chart is the one proposed by Hewitt and Roberts (1969) that has been established for vertical flow in pipes of constant cross section. The flow map for downstream shows that the test case precedent in Table 1 is residing on the slug and churn, in contrast to the observation during the experiment that showed that the flow pattern is only churn flow. This is because some experimental conditions of the present work do not correspond to the standard conditions of Hewitt and Roberts' (1969) map.

\section{CONCLUSIONS}

- When air discharge increases, the volume and amount of bubbles increases. Also, as continuous air discharge increases, flow turbulence increases as does the velocity of generating eddies.

- The volume of bubbles decreases when water discharge increases. Also, as continuous water discharge increases, the flow is more turbulent and unstable and eddies are stronger.

- The effect of increases of water discharge on the turbulence is higher than the effect of increases of air discharge because the water density is higher and, thus, the inertia force is greater for the case of water.

- The obstruction increases the flow turbulence because it divides the bubble and its effect is clearer whenever the bubble size is larger.

- when water discharge increases, the mean pressure difference increases by $33 \%$ as when air water discharge increases, the mean pressure difference increases by $24 \%$. 
- When the opening angle increases, the mean pressure difference decreases due to the losses caused by eddies being stronger

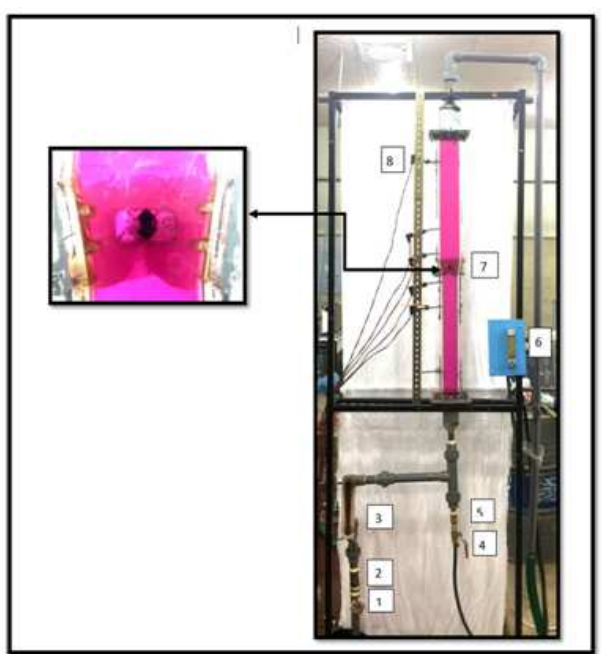
1. Gate Valve
3. Water Flow Meter
5. Check Valve
7. Divergence Section
2. Check Valve
4. Gate Valve
6. Air Flow Meter
8. Pressure Sensor

Figure 1(a): Photographic View of the Experimental Setup

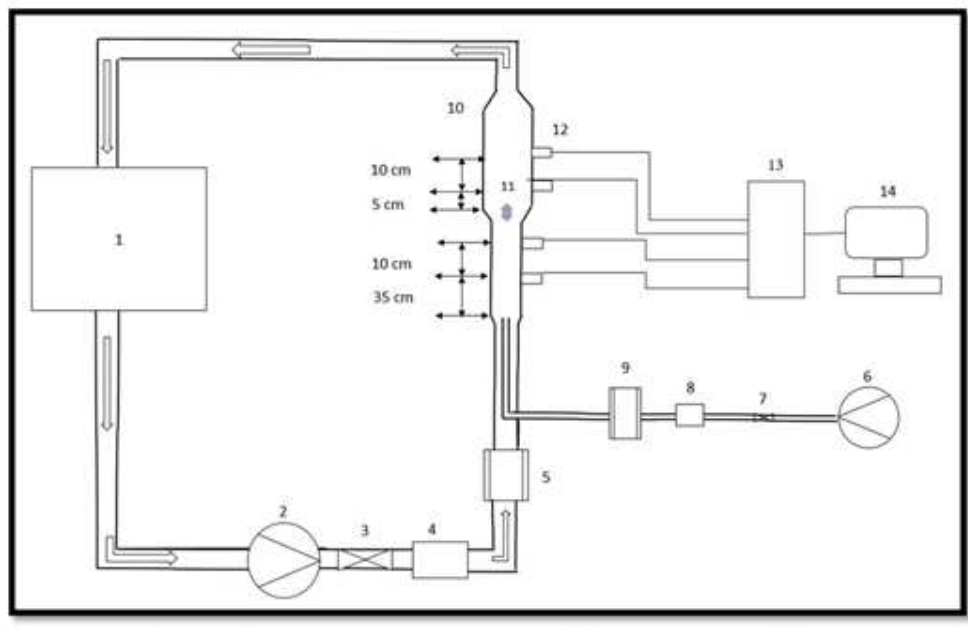
1. Tank
4. Check Valve,
7.Gate Valve,
10. Test Section
13. Pressure Interface
2. Centrifugal Water Pump
5. Water Flow Meter
8. Check Valve
11. Obstruction
14. Personal Computer
3. Gate Valve
6. Air Compressor
9. Air flow Meter
12. Pressure sensor

Figure 1(b): Schematic Diagram of the Experimental Setup 


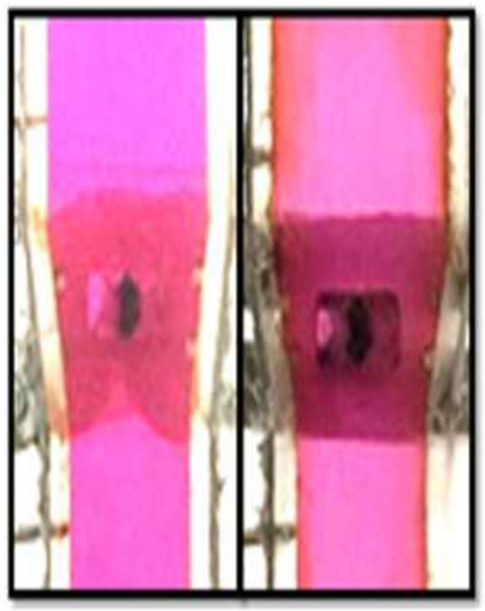

(a). Opening Angle=10 Degrees

(b). Opening Angle $=15$ Degrees

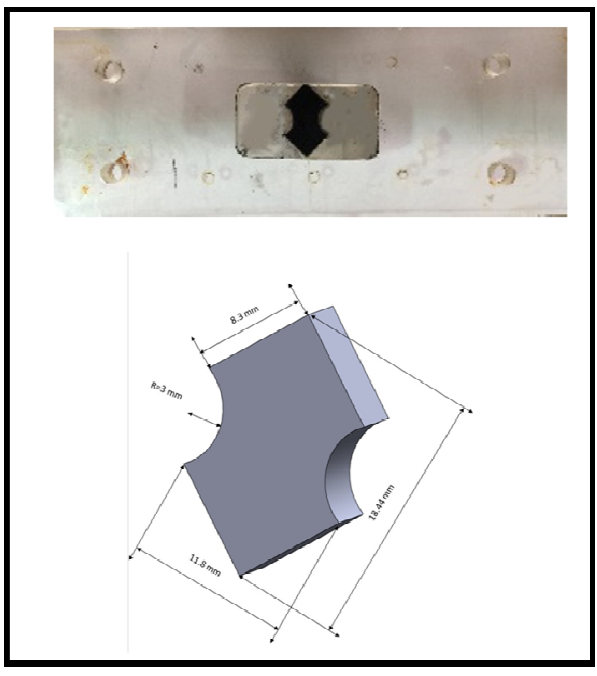

Figure 3: The Obstruction with Dimensions
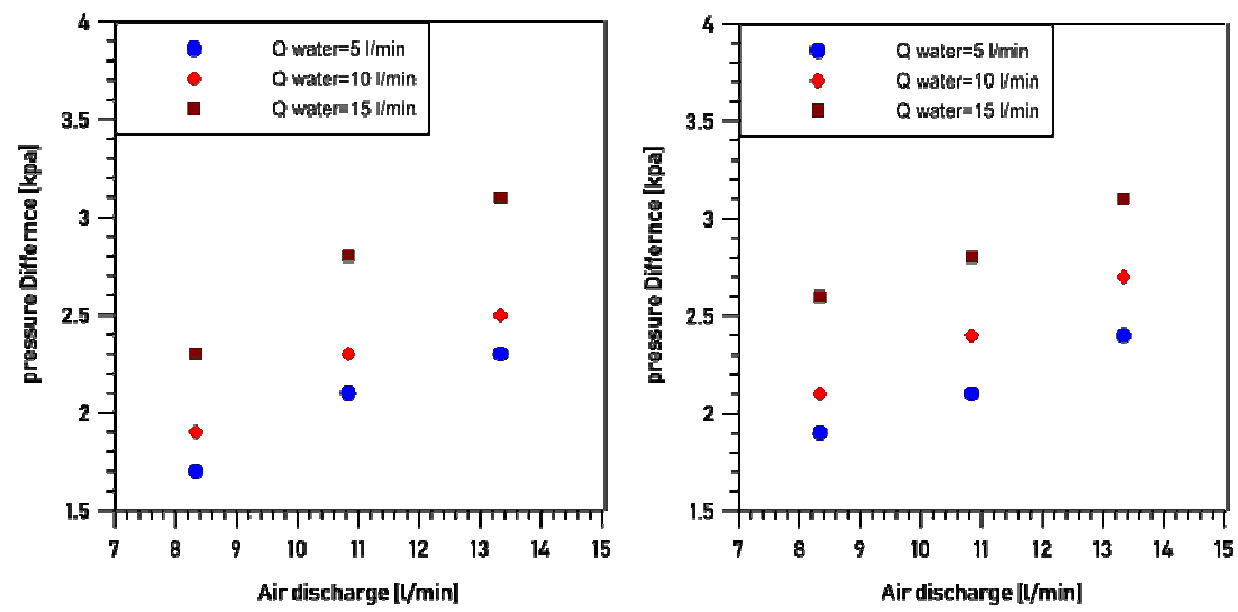

Figure 4: Means the Pressure Difference with Air Discharge for Different Values of Water Discharge

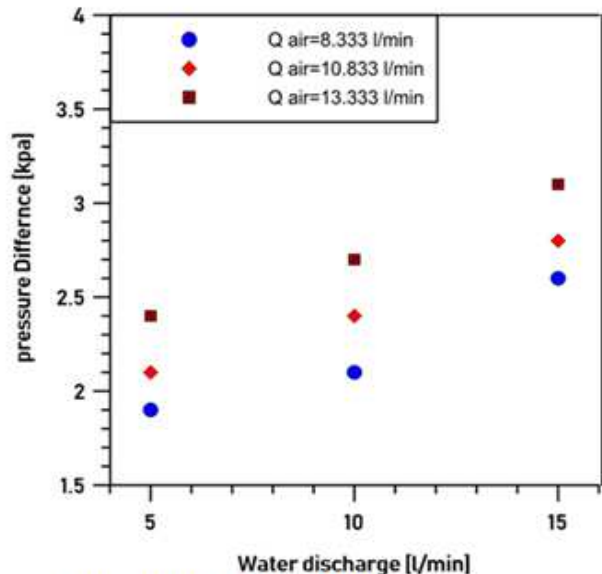

(a). Opening Angle $=10$ degrees

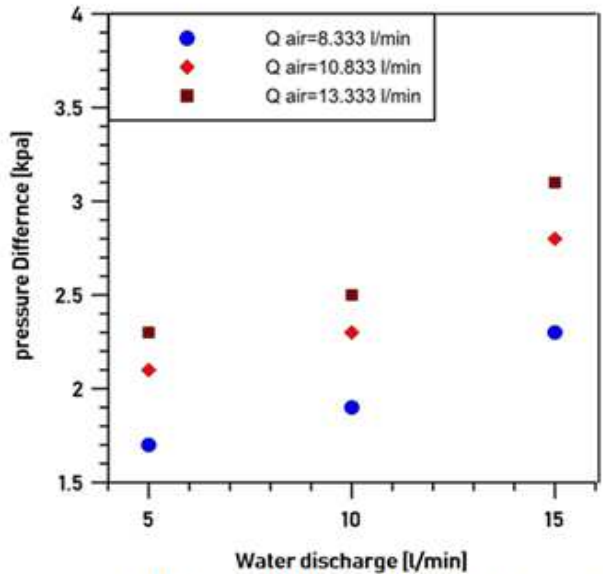

(b). Opening Angle $=15$ degrees

Figure 5: Means the Pressure Difference with Water Discharge for Different Values of Air Discharge 


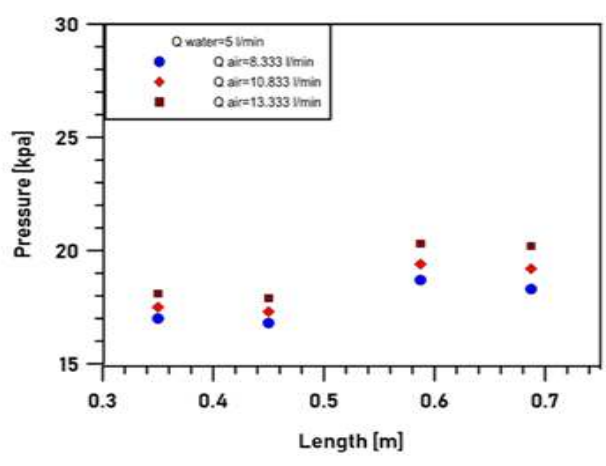

(a). $Q$ Water $=51 / \mathrm{min}$

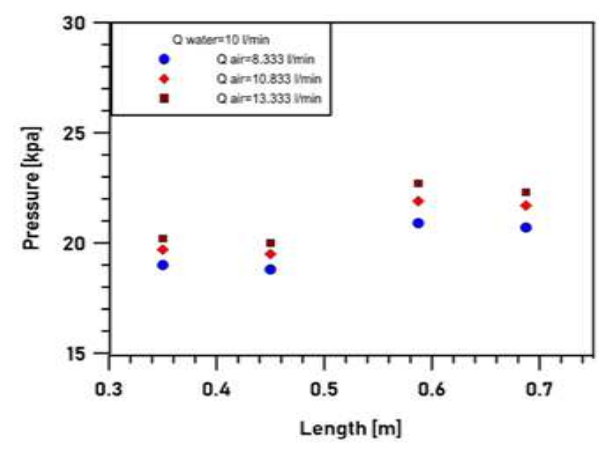

(b). $Q$ Water $=10 \mathrm{l} / \mathrm{min}$

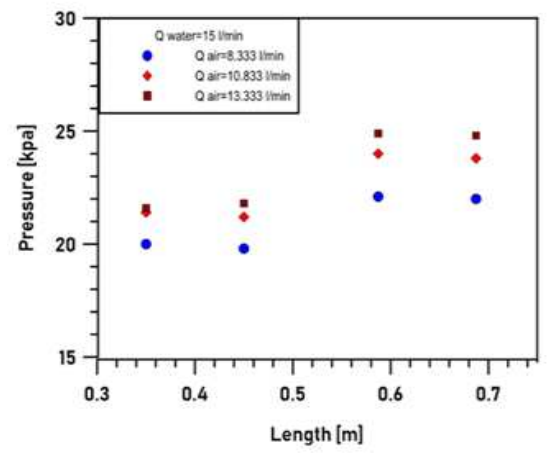

(c). Q Water $=15 \mathrm{l} / \mathrm{min}$

Figure 6: Effect of Water Discharge on Pressure Profile at Opening Angle=10 degrees

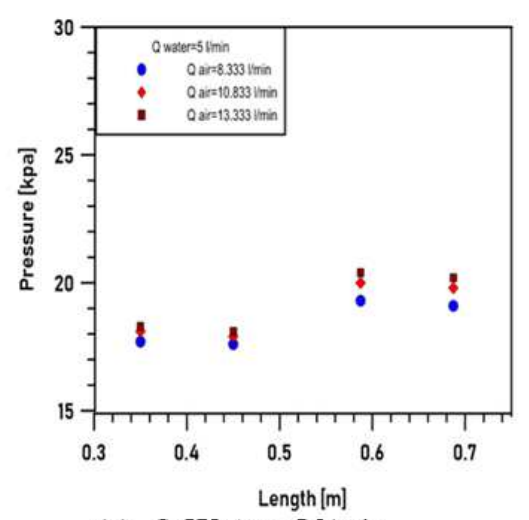

(a). Q Water $=5 \mathrm{l} / \mathrm{min}$

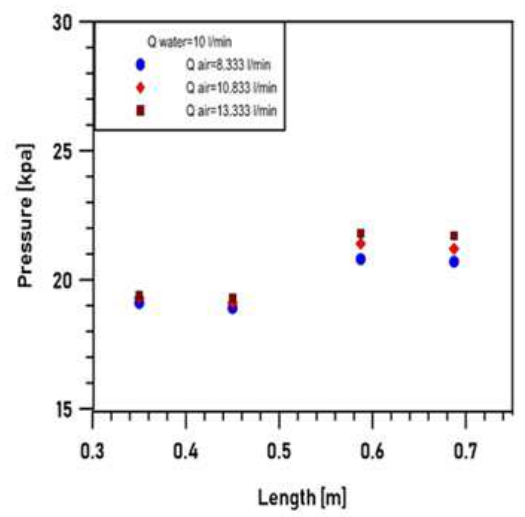

(b). Q Water $=10 \mathrm{l} / \mathrm{min}$

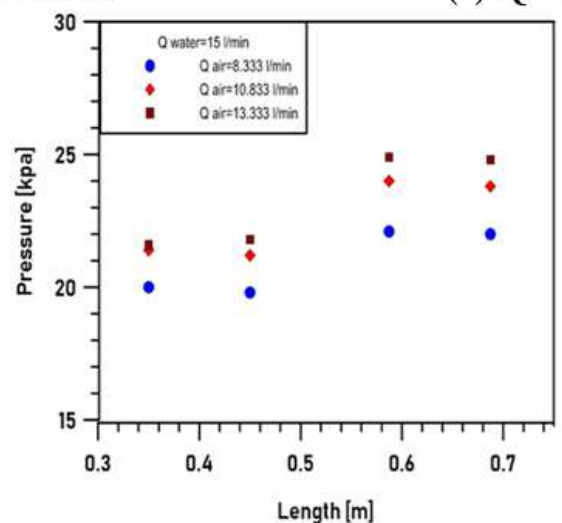

(c). Q Water $=15 \mathrm{l} / \mathrm{min}$

Figure 7: Effect of Water Discharge on Pressure Profile at Opening Angle=15 Degrees 


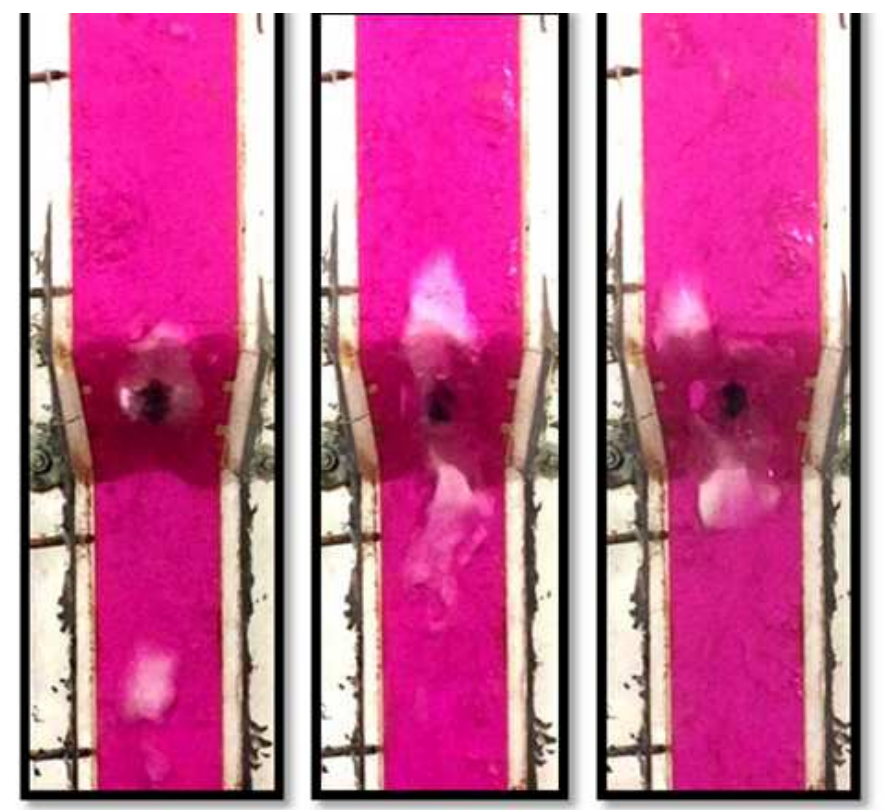

$\begin{array}{llll}\text { (a). Q Air }=8.333 \mathrm{l} / \mathrm{min} & \text { (b). Q Air }=10.833 \mathrm{l} / \mathrm{min} & \text { (c). Q Air=13.333 } \mathrm{l} / \mathrm{min}\end{array}$

Figure 8: Photographs of the Two-Phase Flow Behavior for $Q$ water=5 l/min and Opening Angle=10
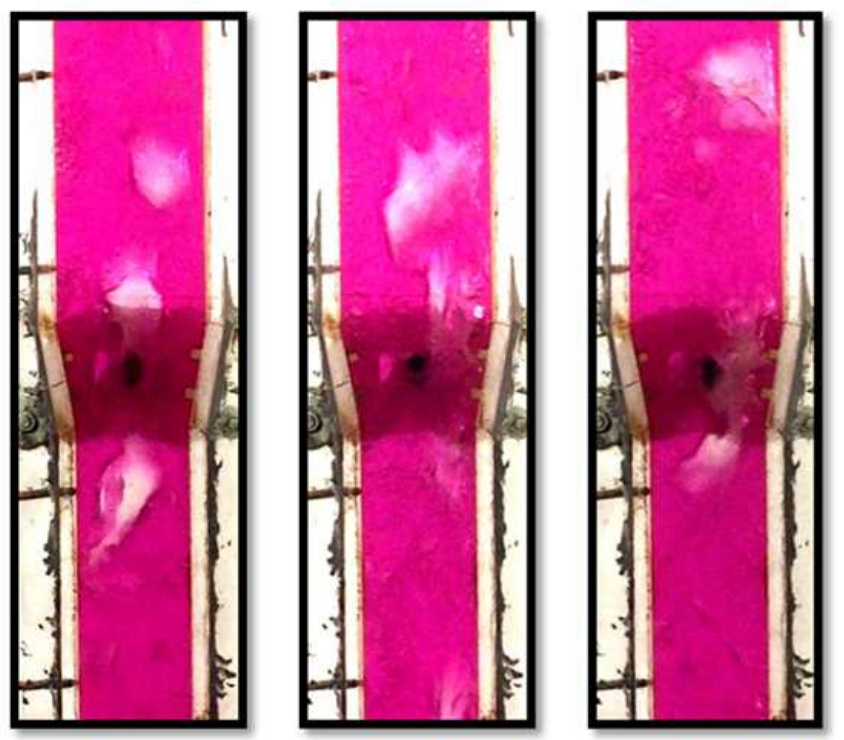

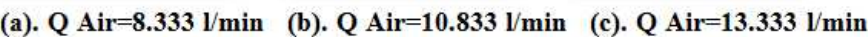

Figure 9: Photographs of the two-Phase Flow Behavior for $Q$ Water=10 1/min and Opening Angle=10 

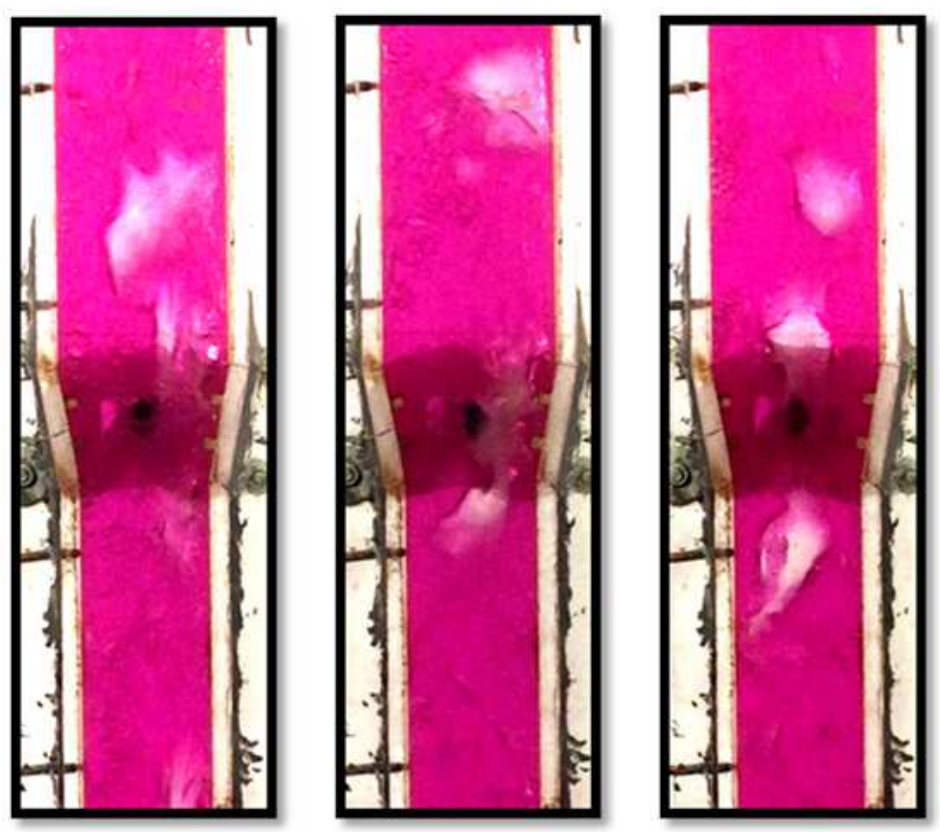

a. Q Air $=8.333 \mathrm{l} / \mathrm{min}$

b. $Q$ Air $=10.833 \mathrm{l} / \mathrm{min}$ c. $Q$ Air $=13.333 \mathrm{l} / \mathrm{min}$

Figure 10: Photographs of the Two-Phase Flow Behavior for $Q$ Water=15 $1 / \min$ and Opening Angle=10

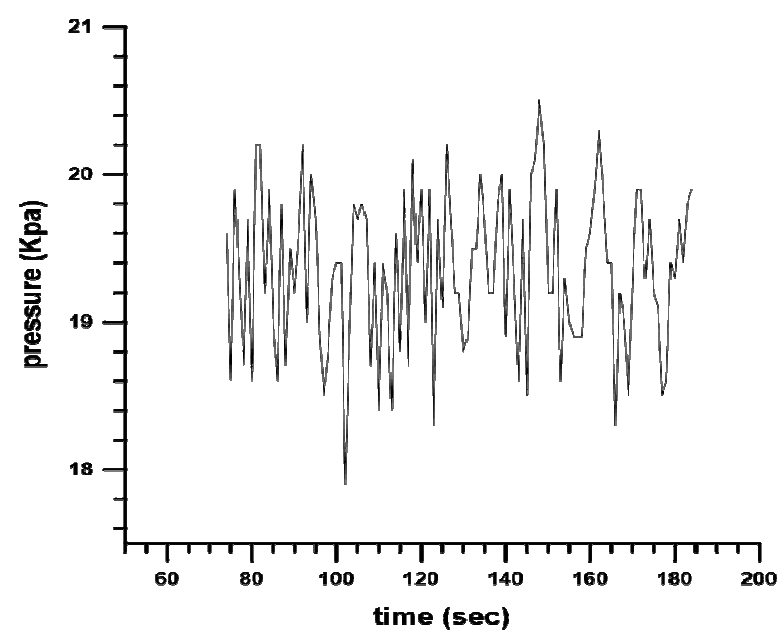

Figure 11: Effect of Time Evolution of Pressure

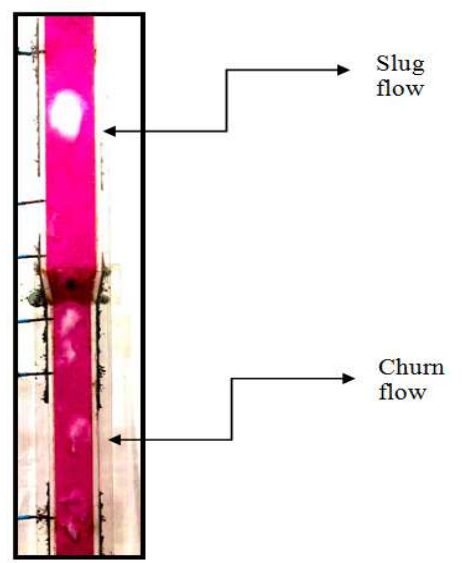

Figure 12: Flow Pattern in Test Section 


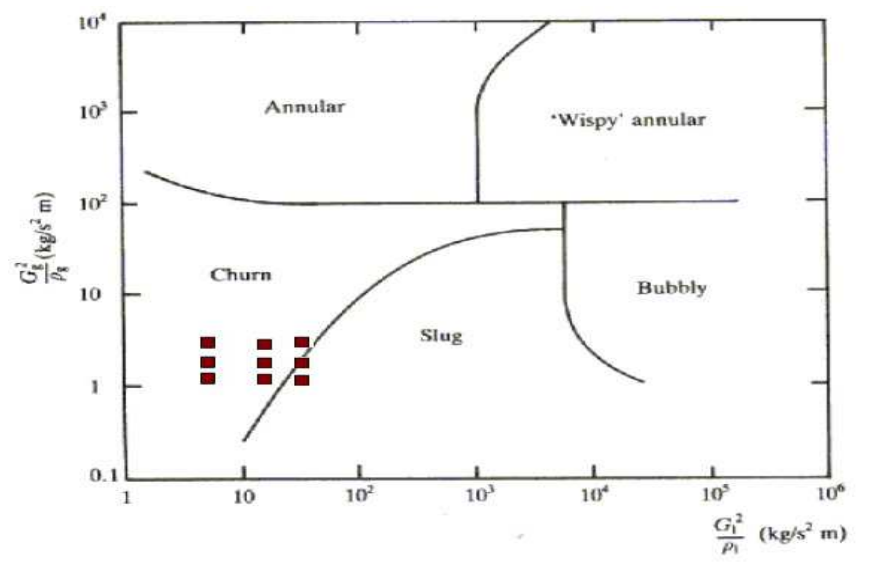

Figure 13: Flow Pattern Map of Hewitt and Roberts (1969)

\section{REFERENCES}

1. Abadie, Thomas, Joëlle Aubin, Dominique Legendre, and Catherine Xuereb. 2012. "Hydrodynamics of Gas-Liquid Taylor Flow in Rectangular Microchannels." Microfluidics and Nanofluidics 12 (1-4): 355-69. https://doi.org/10.1007/s10404-0110880-8.

2. Abed, Esam M, Riyadh S Al, and O F Mech. n. d. "Experimental Study of Two-Phase Flow Around Hydrofoil in Open Channel," no. 2006.

3. Ahmadpour, A., S. M. A. Noori Rahim Abadi, and R. Kouhikamali. 2016. "Numerical Simulation of Two-Phase Gas-Liquid Flow through Gradual Expansions/contractions.” International Journal of Multiphase Flow 79. Elsevier Ltd: 31-49. https://doi.org/10.1016/j.ijmultiphaseflow.2015.10.008.

4. Ansari, M. R., and B. Arzandi. 2012. "Two-Phase Gas-Liquid Flow Regimes for Smooth and Ribbed Rectangular Ducts." International Journal of Multiphase Flow 38 (1). Elsevier Ltd: 118-25.

https://doi.org/10.1016/j.ijmultiphaseflow.2011.08.008.

5. Deniz, E., and N. Eskin. 2011. "Numerical Analysis of Adiabatic Two-Phase Flow through Enlarging Channel." Proceedings of the 24th International Conference on Efficiency, Cost, Optimization, Simulation and Environmental Impact of Energy Systems, ECOS 2011.

6. Frank, Th., H.-M. Prasser, M. Beyer, and S. Al Issa. 2007. "Gas-Liquid Flow around an Obstacle in a Vertical Pipe - CFD Simulation \& Comparison to Experimental Data.” 6th International Conference on Multiphase Flow, ICMF 2007, no. 135: 114.

7. Ghajar, A. J. 2005. "Non-Boiling Heat Transfer in Gas-Liquid Flow in Pipes: A Tutorial.” Journal of the Brazilian Society of Mechanical Sciences and Engineering 27 (1): 46-73. https://doi.org/10.1590/S1678-58782005000100004.

8. Jaafer Habeeb, Laith, and Riyadh S. Al-Turaihi. 2013. "Experimental Study and CFD Simulation of Two-Phase Flow around Multi-Shape Obstacles in Enlarging Channel." American Journal of Mechanical Engineering 1 (8): 470-86. https://doi.org/10.12691/ajme-1-8-1.

9. Kourakos, V. G., P. Rambaud, S. Chabane, D. Pierrat, and J. M. Buchlin. 2009. "Two-Phase Flow Modelling within Expansion and Contraction Singularities” 63: 27-43. https://doi.org/10.2495/MPF090031.

10. Li, Xiangbin, Guoyu Wang, Mindi Zhang, and Wei Shyy. 2008. "Structures of Supercavitating Multiphase Flows." International Journal of Thermal Sciences 47 (10): 1263-75. https://doi.org/10.1016/j.ijthermalsci.2007.11.010. 
11. Mamdouh, T., Khalil, D. S., Anis, W. R., \& Ragai, H. Finfetlow Power Capacitive Pressure Sensor Readout Circuit.

12. Rogero, Edurne Carpintero. 2009. “Experimental Investigation of Developing Plug and Slug Flows,” 138.

13. Zhu, S., H. Blackburn, and B. Anderson. 2009. "Numerical Simulations of Bubble Dispersion over a Hydrofoil." 7th International Conference on CFD in the Minerals and Process Industries, no. December: 1-6. 